\title{
A Study On Comparison Of Pain Score Between Upper Limb And Lower Limb Fractures
}

\author{
K. A. Baharuddin, M. H. Fauzi, M. F. Mohd Shukri, N. Yaacob, and M. A. Abu Bakar
}

\begin{abstract}
Introduction: Pain is the most common chief complaint of patients presenting to Emergency Department (ED). Pain is not simply a signal for tissue injury, but also a signal to seek repair and recuperation. The aim of this study was to determine whether upper limb (UL) or lower limb (LL) fracture has more pain and to evaluate the association between types of fracture (UL vs LL) with adequacy of pain relief.

Methodology: A study was conducted from July to October 2005 in ED, Hospital Universiti Sains Malaysia (HUSM). Patients who fulfill the inclusion criteria were selected. Paramedics in charged were the assistants; at the same time became the observer. The paramedics were not involved in the decision making for pain management. Pain severity score was assessed by using Numeric Rating Scale (NRS).

Results: 42 patients were enrolled. $85.7 \%(n=36)$ were male and $14.3 \%$ were female. Mean age is 29.6 years old. Mean NRS on arrival for $U L$ and $L L$ fractures were $6.47 \pm 1.70$ and $7.80 \pm$ 2.53 respectively. Mean NRS for mixed fractures (both UL and LL) was 7.60 \pm 3.36. There was no statistically significant association between fracture sites and analgesic administration ( $p$ value $=0.300$ ). There were $70.6 \%$ and $70.0 \%$ of the patients with $U L$ and $L L$ fractures had adequate pain relief whereas $80 \%$ of patients with mixed fractures had adequate pain relief (p value $=0.902)$.
\end{abstract}

Conclusion: LL and mixed fractures had more pain score on arrival but there was no statistically significant association between fracture sites and analgesics administration and no association between fracture sites with adequacy of pain relief.

Index Terms - fracture pain, upper limb, lower limb, pain relief.

\section{INTRODUCTION}

Pain is the most common chief complaint of patients presenting to Emergency Department (ED) [1]. Pain is not simply a signal for tissue injury, but also a signal to seek repair and recuperation. Any fractures cause significant pain to the patients and require immediate pain assessment and treatment [2].

Most fractures are caused by sudden and excessive force that lead to the bone breaks at the point of impact with damage of the soft tissues [3]. Upon fracture, there is mechanical distortion of periosteum and pain signaling that lead to immediate sharp and intense pain [4]. Fracture also leads to inflammatory response and releases of mediators that results in severe pain, requires efficient pain

Published on June 13, 2020

K. A. Baharuddin, Universiti Sains Malaysia, Malaysia.

(corresponding e-mail: amararyff@ usm.my)

M. H. Fauzi, Universiti Sains Malaysia, Malaysia.

M. F. Mohd Shukri, Universiti Sains Malaysia, Malaysia.

N. Yaacob, Universiti Sains Malaysia, Malaysia.

M. A. Abu Bakar Universiti Sains Malaysia, Malaysia. management [5].

As the incidence of fracture is expected to increase due to change in life style [6], its management should be of importance. Traditionally fracture pain was not properly treated in ED, even with documented moderate or severe pain [7]. Managing pain requires mechanism-guided, evidence-based and personalised [8]. Luckily, many of the emergency doctors have address the undertreatment of pain in ED and improving the quality of care [1]. Focusing on adequate assessment, accurate diagnosis and comprehensive treatment may be inadequate [8].

Pain score for fracture of upper limb (UL) or lower limb (LL) was never compared specifically. There was an article comparing about fracture pain and soft tissue injury pain that showed no statistically significant between these two [9]. Another study about managing significant acute trauma pain in ED had 50\% of the patients with fracture and another $50 \%$ of the patients with soft tissue injury. All the patients had pain score based on numeric rating scale (NRS) of 6 or more [10]. Nevertheless, the health-related quality of life showed LL injuries had the highest impact in comparison to UL injuries [11]. The aims of this study are to determine whether UL or LL fractures has more pain and to evaluate the association between types of fracture (UL vs LL) with adequacy of pain relief.

\section{Methodology}

It was an observational study carried out from July 2005 to October 2005 in Hospital Universiti Sains Malaysia (USM). Hospital USM is a tertiary center located at the northeast of Peninsular Malaysia with 750 beds available for adult and pediatric patients. Ethical approval was obtained from the University Sains Malaysia, Human Ethics Committee.

Patients (aged 12 years and above) with isolated extremity fractures were enrolled based on convenience sampling. Other inclusion criteria are fully conscious with Glasgow Coma Scale of 15/15, hemodynamically stable and must be free from alcohol influence or intoxications. Exclusion criteria are polytrauma, pelvic fracture or rib fracture and duration of fracture was more than 12 hours. Pregnant patients and patients with a significant language barrier were also excluded.

One paramedic in charged was assigned to assist the doctor on duty and at the same time became an observer. The paramedic was not involved in decision making for managing fracture patients. To date, there are no analgesic guidelines to guide doctors in prescribing analgesics in such patients. No effort was allowed to influence the doctor on what type of analgesic was to be prescribed. All patients in 
this study were asked for informed consent prior to participating in the study. Paramedics would review the patients' record for presence or absence of pain assessment and pain severity score. If absent, the paramedic would complete the pain assessment during admission or disposition to the ward.

For standardization of pain severity score, it was decided to use the NRS. NRS is better than Visual Analoque Score (VAS) for pain assessment in emergency care setting, particularly involving orthopedic trauma or fracture. Reliability, construct validity and concurrent validity of the NRS have been documented previously in both non-ED and ED patients' population [12]. A horizontal 0 to $10 \mathrm{NRS}$ was used to measure pain severity. The words 'no pain' and 'worst possible pain' were found at 0 and 10 ends of the scale, respectively. The minimum clinically significant different (MCSD) for pain relief is 2 or more [12,13,14]. If analgesics were administered to the patients; type, total dosage and route would be written in the questionnaires. Pain assessment were assessed on 2 occasions which were 30 minutes after analgesia and before disposition to the ward. The main study outcome was the pain score for UL or LL or mixed fractures. Mixed fracture is when a patient had both UL and LL fractures.

\section{RESULTS}

A total of 42 patients A total of $42(n=42)$ patients were enrolled in the study. Of these patients, $85.7 \%(n=36)$ were male and $14.3 \%(n=6)$ were female. All of them were Malays. The mean age was 29.6 years old. There were 17 patients and 20 patients who had UL fracture and LL fracture respectively. Only 5 patients had mixed fracture. The mean age for fracture upper limb (UL) was 29.9 years old, lower limb (LL) fracture was 32.2 years old and mixed fracture was 18.0 years old.

Mean age for patients with mild pain, moderate pain and severe pain were 49.40 years old $(\mathrm{SD} \pm 24.48), 28.47$ years old $(\mathrm{SD} \pm 16.34)$ and 25.60 years old $(\mathrm{SD} \pm 13.14)$ respectively. 30 patients were given analgesics with mean NRS 7.83 ( $\mathrm{SD} \pm 2.14)$ whereas 12 patients did not receive any analgesics with NRS 5.75 ( $\mathrm{SD} \pm 2.34$ ). 29\% of patients with UL fracture did not receive analgesic whereas $35 \%$ of patients with LL fracture did not receive any analgesics. All patients with mixed fractures receive analgesic. The most common fracture in upper extremities was distal end radius whereas the most common fracture for LL were tibial and fibula fractures, followed by fracture of metatarsal. Analgesic of choice where non-steroidal anti-inflammatory drugs (NSAID) accounts for $46.7 \%$, followed by opioids $(40 \%)$ and tramadol $(13.3 \%)$.

TABLE I: DESCRIPTIVE DATA OF AGE, NRS ON ARRIVAL AND NRS DURING DISPOSITION FROM ED

\begin{tabular}{l|c|c|c|c|c|c}
\hline \multirow{2}{*}{} & \multicolumn{2}{|c|}{$\begin{array}{c}\text { UL \# } \\
\mathrm{n}=17\end{array}$} & \multicolumn{2}{c|}{$\begin{array}{c}\text { LL \# } \\
\mathrm{n}=20\end{array}$} & \multicolumn{2}{c}{$\begin{array}{c}\text { Mixed \# } \\
\mathrm{n}=5\end{array}$} \\
\cline { 2 - 7 } & Mean/n & $\mathrm{Sd} / \%$ & Mean /n & $\mathrm{Sd} / \%$ & Mean/n & $\mathrm{Sd} / \%$ \\
\hline Age (years) & 29.9 & 16.2 & 32.2 & 19.5 & 18.0 & 3.1 \\
\hline No. of patient & 17 & 40.5 & 20 & 47.6 & 5 & 11.9 \\
\hline NRS arrival & 6.47 & 1.70 & 7.80 & 2.53 & 7.60 & 3.36 \\
\hline NRS disposition & 3.30 & 1.45 & 4.24 & 2.24 & 3.95 & 2.08 \\
\hline * Standard Deviation \\
\# Fracture
\end{tabular}

TABLE II: ASSOCIATION OF NRS ON ARRIVAL WITH ANALGESIC ADMINISTRATION

\begin{tabular}{ccccccc}
\hline & \multicolumn{2}{c}{ NRS } & $\begin{array}{c}\text { Mean } \\
\text { diff. }\end{array}$ & \multicolumn{2}{c}{$95 \% \mathrm{CI}$} & \multirow{2}{*}{ P value } \\
\cline { 2 - 5 } & $\begin{array}{c}\text { Mean } \\
(\mathrm{Sd})\end{array}$ & & lower & upper & \\
\hline Analgesic & $\mathrm{Y}$ & $\begin{array}{c}7.83 \\
(2.14)\end{array}$ & 2.083 & 0.569 & 3.597 & 0.008 \\
administration & $\mathrm{N}$ & $\begin{array}{c}5.75 \\
(2.34)\end{array}$ & & & & \\
\hline
\end{tabular}

\section{$\mathrm{Y}=\mathrm{Yes}$}

$\mathrm{N}=\mathrm{No}$

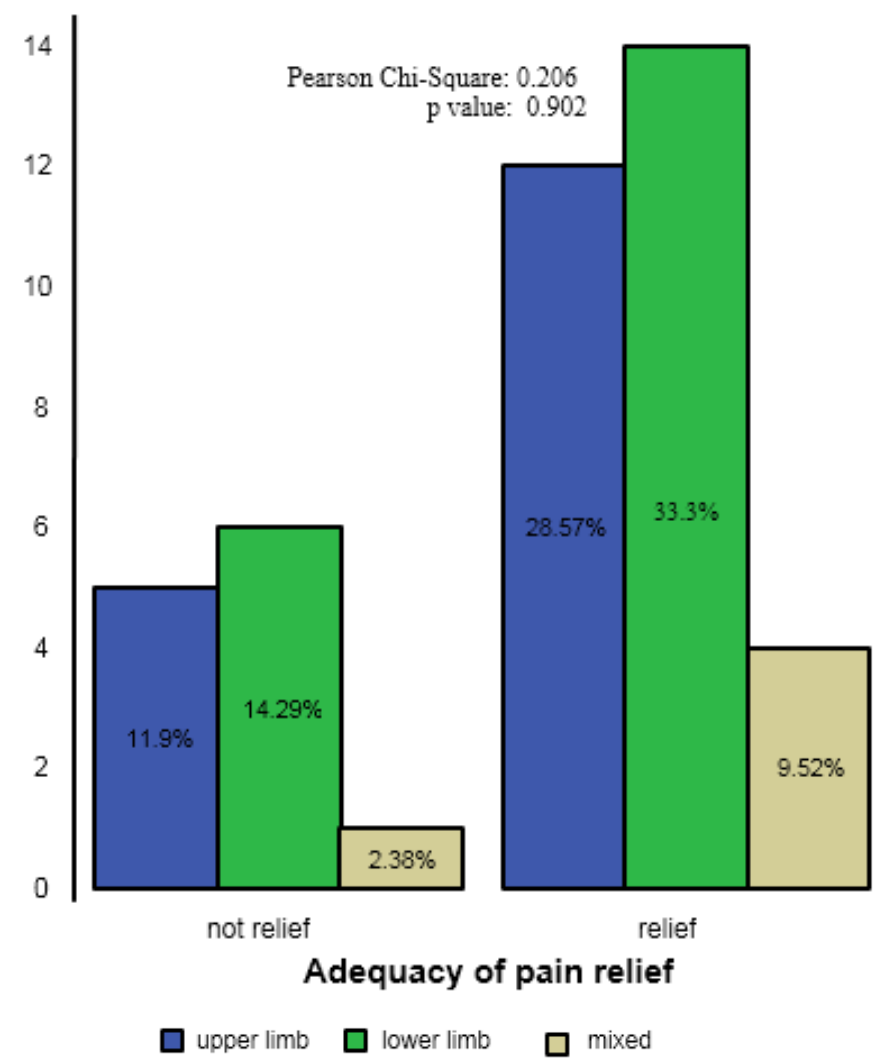

Fig. 1 Association between fracture site with adequate pain relief.

Fig. 1 shows the bar chart of association between adequacy of pain relief with fracture site. Adequacy of pain relief is achieved with reduction in NRS 2 or more points.

\section{DISCUSSION}

Effective pain management is a very crucial component in the ED. In order to give the best pain management, the problem has to be identified by objectively evaluating the pain score [2]. Asking for pain score and considering pain as fifth vital signs improves physician attention for pain evaluation and treatment [15].

A total of 42 patients were involved in the study with male and female patients were $85.7 \%$ and $14.3 \%$ respectively. The mean age was 29.6 years old. This is comparable with the worldwide data that male, especially those between 15 and 44 years old, are the extremely affected group of patients that involve with road traffic accidents that may lead to fracture and fatalities [16].

From the analysis, it is more likely that younger patients perceived more pain than elderly patients. This result is consistent with old study regarding age-related differences in pain where there was $16 \%$ increase in pain threshold 
between adults 30-64 years old and that the age effect was greater in women [17]. One cross-sectional, observational study done in 2 urbans academic EDs found that elderly patients experienced less acute pain than their younger counterparts in response to a standardized stimulus in a clinical setting [18]. However, latest systematic review with meta-analysis has inconclusive results but there is a tentative evidence that old adults may be more sensitive to mechanically-evoked pain [19].

Table I shows the mean NRS on arrival for UL fracture, LL fracture and mixed fractures were 6.47, 7.80 and 7.60 respectively. NRS during disposition were 3.30, 4.54 and 4.32 for UL fracture, LL fracture and mixed fractures respectively. Generally, LL fracture is more painful compare to UL fracture with the difference of NRS more than 1. Mixed fracture had almost similar pain score in comparison with LL fracture on arrival and during disposition.

The most common fracture in UL fracture and LL fracture were distal end radius fracture and tibial fibula fractures respectively. This finding is comparable with a hospitalbased study in North India [20]. However, our data showed we had more LL fractures compared to UL fracture even though previous studies found UL fractures were more common than LL fractures [21]. Possible explanation is most of the patients with uncomplicated UL fractures are treated in green zone and do not warrant admission.

In this study, NSAID was the analgesic of choice for managing fracture pain. Based on the review of articles about option of pain management in ED, NSAID is one of the commonest drugs to be prescribed in ED [22]. There were $40 \%$ of cases had received opioids for pain management. Considering mean NRS for LL fracture and mixed fractures were under severe pain, prescription of intravenous opioid was appropriate and should be encouraged to avoid oligoanalgesia [23]. A small percentage of patients were administered with intravenous tramadol. Tramadol is not a controlled drug under the Dangerous Drugs Act (DDA) and many medical officers in our hospital are familiar with this drug, mainly for treating acute dyspepsia. Another possible reason for the preference of tramadol is some patients were having moderate pain. However recent evidence discouraged the use of tramadol in managing acute pain in ED [24].

Based on Table II, $28.6 \%$ of patients with mean NRS of 5.75 did not receive any analgesia. Even though the number of patients were small, analgesia should be offered to all patients with pain [2]. Possible explanation is the way patient's response towards the pain. A patient's culture can strongly influence perception of pain and how pain is expressed, indirectly affect the pain management [25]. Study from neighbourhood country showed that Malays descent had lower pain severity compared with Chinese and Indian participants. Since our patients were all Malays, they might tolerate to the pain and affect the decision for pain management [26]. Underrated the patients' pain score are not uncommon among healthcare provider [27]. Those who appear quiet and comfortable may not receive analgesics, therefore affect their pain management [25].

There is no consensus on defining adequate pain relief. A statistically significant difference in pain reduction does not necessarily indicate clinically adequate pain relief [28]. In one of the cohort studies, the MCSD in NRS pain scores was $1.39 \pm 1.05$ [12], although another study found the MCSD for the NRS is 1.3 [13]. Latest study defines adequate pain relief as reduction of 50 percent or more of the initial NRS score after receiving the analgesic [29]. However, in our study, adequate pain relief is defined based on NRS difference for pre and post treatment is a score of 2 or more, based on the MCSD.

Fig. 1 shows equal pattern of adequate and inadequate pain relief between fracture sites. There is no correlation between fracture sites and adequacy of pain relief. Further statistical analysis using Pearson Chi-Square shows that there is no statistically significant association between fracture site with adequacy of pain relief ( $p$ value $=0.902$ ) . This result is comparable with previous study that found no statistically significant different of pain score between fracture and soft tissue injury. There was also no significant pain score difference before discharged [9]. However, in general, the mean difference of pain score for LL and mixed fractures are more than UL fracture.

The present study was limited by the small sample size and it was likely underpowered to detect a significant difference. This is almost similar with previous study with 103 patients [9]. The next limitation is data sampling. Due to the lack of the availability of investigation staff, subjects were not enrolled consecutively, but as a convenience sample.

\section{CONCLUSION}

LL and mixed fractures had more pain score on arrival compare to UL fracture. There was no statistically significant association between fracture sites and analgesics administration and no association between fracture sites with adequacy of pain relief.

\section{CONFLICT OF INTEREST}

The authors declare that they have no conflict of interest that competes with any of the contents of the manuscript.

\section{ACKNOWLEDGMENT}

We thank gratefully the staff in the Emergency Department, Hospital USM.

\section{REFERENCES}

[1] Ducharme, J. (2000). Acute pain and pain control: state of the art. Annals of Emergency Medicine, 35(6), 592-603.

[2] Dale, J., \& Bjørnsen, L. P. (2015). Assessment of pain in a Norwegian Emergency Department. Scandinavian Journal of Trauma Resuscitation and Emergency Medicine, 23(1), 86.

[3] Apley A.G, Solomon L. System of Orthopaedics and Fractures Seventh Edition. ELBS.1993.

[4] Santy, J., \& Mackintosh, C. (2001). A phenomenological study of pain following fractured shaft of femur. Journal of Clinical Nursing, 10(4), 521-527.

[5] Alves, C. J., Neto, E., Sousa, D. M., Leitao, L., Vasconcelos, D. M., Ribeiro-Silva, M., \& Lamghari, M. (2016). Fracture pain-traveling unknown pathways. Bone, $85,107-114$

[6] Court-Brown, C. M., \& Caesar, B. (2006). Epidemiology of adult fractures: a review. Injury, 37(8), 691-697.

[7] Brown, JC., Klein, EJ., Lewis, CW., Johnston, BD., \& Cummings, P. (2003). Emergency department analgesia for fracture pain. Annals of Emergency Medicine, 42(2), 197-205.

[8] Cheng, J. (2018). State of the art, challenges, and opportunities for pain medicine. Pain Medicine, 19(6), 1109-1111. 
[9] Pines JM, Perron AD. Oligoanalgesia in ED patients with isolated extremity injury without documented fracture. Am J Emerg Med. 2005; 23(4): 58.

[10] Baharuddin, K.A., Rahman, NHN., Wahab, SFA., Halim, NA., \& Ahmad, R. (2014). Intravenous parecoxib sodium as an analgesic alternative to morphine in acute trauma pain in the emergency department. International Journal of Emergency Medicine, 7(1), 2.

[11] Sluys, K. P., Shults, J., \& Richmond, T. S. (2016). Health related quality of life and return to work after minor extremity injuries: A longitudinal study comparing upper versus lower extremity injuries. Injury, 47(4), 824-831.

[12] Kendrick DB, Strout TD. The minimum clinically significant difference in patient-assigned numeric scores for pain. American Journal of Emergency Medicines. 2005; 23: 828-832.

[13] Bijur PE, Latimer CT, Gallagher EJ. Validation of a verbally administered numerical rating scale of acute pain for use in the emergency department. Acad Emerg Med. 2003; 10: 390-392.

[14] Strout TD, Burton JH. Clinically significant change in physician assigned numeric pain rating scores. Am J Emerg Med. 2004; 22: 243 245.

[15] Fosnocht DE, Swanson ER, Barton ED. Changing attitudes about pain and pain control in Emergency Medicine. Emerg Med Clin N Am. 2005; 23: 297-306.

[16] Mohammed, A. A., Ambak, K., Mosa, A. M., \& Syamsunur, D. (2019). A review of the traffic accidents and related practices worldwide. The Open Transportation Journal, 13(1).

[17] Sherman ED, Robillard E. Sensitivity to pain in relationship to age. $J$ Am Geriatr Soc.1964; 12: 1037.

[18] Li SF. Effect of age on acute pain perception of a standardized stimulus in the emergency department. Ann Emerg Med. 2001; 38(6): 644-7.

[19] El Tumi, H., Johnson, M. I., Dantas, P. B. F., Maynard, M. J., \& Tashani, O. A. (2017). Age-related changes in pain sensitivity in healthy humans: A systematic review with meta-analysis. European Journal of Pain, 21(6), 955-964.

[20] Awasthi, B., Raina, S. K., Kumar, N., Sharma, V., Kalia, S. \& Thakur, L. (2016). Pattern of extremity fractures among patients with musculoskeletal injuries: a hospital based study from North India. Journal of Medical Society, 30(1), 35.

[21] Meena RK, Singh AM, Singh CA, Chishti S, Kumar AG, Langshon R. Pattern of fractures and dislocations in a tertiary hospital in North East India. Int J Epidemiol 2013;11:13-5.

[22] Abdolrazaghnejad, A., Banaie, M., Tavakoli, N., Safdari, M., \& Rajabpour-Sanati, A. (2018). Pain management in the emergency department: a review article on options and methods. Advanced Journal of Emergency Medicine, 2(4).

[23] Thomas, S. H. (2013). Management of pain in the emergency department. ISRN Emergency Medicine, 2013.

[24] Cisewski, D. H., \& Motov, S. M. (2019). Essential pharmacologic options for acute pain management in the emergency setting. Turkish journal of emergency medicine, 19(1), 1-11.

[25] Pudner, R. (Ed.). (2005). Nursing the surgical patient. Elsevier Health Sciences.

[26] Chan, A., Malhotra, C., Do, Y. K., Malhotra, R., \& Østbye, T. (2011) Self reported pain severity among multiethnic older Singaporeans: Does adjusting for reporting heterogeneity matter?. European Journal of Pain, 15(10), 1094-1099.

[27] Baharuddin, K. A., Mohamad, N., Rahman, N. H. N. A., Ahmad, R., \& Him, N. A. S. N. (2010). Assessing patient pain scores in the emergency department. The Malaysian Journal of Medical Sciences: MJMS, 17(1), 17

[28] Todd, K. H. (1996). Clinical versus statistical significance in the assessment of pain relief. Annals of emergency medicine, 27(4), 439441.

[29] Sokoloff, C., Daoust, R., Paquet, J., \& Chauny, J. M. (2014). Is adequate pain relief and time to analgesia associated with emergency department length of stay? A retrospective study. BMJ open, 4(3), e004288. 